\title{
DETERMINAÇÃO DA CONDUTIVIDADE HIDRÁULICA DA FORMAÇÃO RIO CLARO: ANÁLISE COMPARATIVA ATRAVÉS DE ANÁLISE GRANULOMÉTRICA E ENSAIOS COM PERMEÂMETRO GUELPH E TESTES DE $S L U G$
}

\author{
DETERMINATION OF THE HYDRAULIC CONDUCTIVITY OF THE RIO CLARO FORMATION: \\ COMPARATIVE ANALYSIS THROUGH GRAIN SIZE ANALYSES AND GUELPH PERMEAMETER \\ AND SLUG TESTS.
}

\author{
Andresa Oliva ${ }^{1}$; Chang Hung Kiang ${ }^{2}$ e Maria Rita Caetano-Chang ${ }^{2}$
}

Recebido em 25/06/2004, aceito em 11/07/2005

\begin{abstract}
RESUMO
A exploração de água subterrânea no município de Rio Claro ocorre predominantemente no aquífero Itararé que, além de se situar a profundidades superiores a $150 \mathrm{~m}$, possui baixa produtividade. Devido a esses fatores e ao aumento da necessidade de abastecimento na região, diversas indústrias vêm explorando água do aqǘ́fero Rio Claro, representado pelos arenitos cenozóicos da Formação Rio Claro, cujo potencial e características hidráulicas são pouco conhecidas. Este estudo objetivou avaliar a condutividade hidráulica, utilizando-se de três poços de monitoramento localizados na Unesp - Campus de Rio Claro. Na porção saturada, as condutividades hidráulicas foram determinadas através dos métodos de Hazen e Shepherd, utilizando análises granulométricas, ensaios com permeâmetro Guelph e testes de Slug, estes últimos utilizando as formulações de Hvorslev e Bouwer e Rice. Todos os valores obtidos situam-se entre $10^{-2}$ e $10^{-4}$ $\mathrm{cm} / \mathrm{s}$, conferindo ao Aqüífero Rio Claro excelente permo-porosidade.
\end{abstract}

Palavras chave: condutividade hidráulica, Formação Rio Claro, análise granulométrica, permeâmetro Guelph, testes de Slug.

\begin{abstract}
Groundwater in the county of Rio Claro is predominantly extracted from low productivity wells of the Itararé Aquifer, pumping from depths greater than $150 \mathrm{~m}$. These factors in conjunction with increasing demand for water supply have stimulated many industries to exploit Rio Claro Aquifer, constituted by Cenozoic sediments of the Rio Claro Formation, where hydraulic properties are poorly known. The objective of the present study is to evaluate hydraulic conductivity utilizing three monitoring wells located at the UNESP-Campus Rio Claro. In the saturated zone, hydraulic conductivities were determined by Hazen and Shepherd methods, based on grain size analyses, Guelph permeameter and slug tests. Slug tests were interpreted using formulations of Hvorslev (1951) and Bouwer and Rice (1976). Hydraulic conductivities values determined from these methods range from $10^{-2}$ to $10^{-4} \mathrm{~cm} / \mathrm{s}$, conferring excellent permo-porosity to the Rio Claro Aquifer.
\end{abstract}

Keywords: hydraulic conductivity, Rio Claro Formation, grain size analysis, Guelph permeameter, Slug tests.

\section{INTRODUÇÃO}

No município de Rio Claro, a exploração de águas subterrâneas tem sido implementada em rochas do Subgrupo Itararé que, na região, encontra-se relativamente profundo (de 200 a 500 metros) e caracteriza-se por apresentar baixa produtividade. Além disso, em porções mais profundas as águas desta unidade, apresentam alta salinidade, da ordem de 1000 ppm, comprometendo sua qualidade.

Devido a esses fatores e ao incremento na demanda do abastecimento doméstico, industrial e agropecuário na região de Rio Claro, várias indústrias e propriedades rurais no município vêm utilizando água subterrânea extraída de arenitos da Formação Rio Claro, o qual assentase sobre a Formação Corumbataí.

Esse aquíffero atende de maneira satisfatória à demanda atual, mas um incremento muito elevado na exploração do mesmo pode gerar problemas no suprimento de água. Diante desse quadro desfavorável, torna-se necessário um bom conhecimento de suas características permoporosas.

Visando melhor conhecer as propriedades hidráulicas da Formação Rio Claro, efetuou-se determinação de condutividade hidráulica, utilizando três tipos de ensaios: análise granulométrica, método Guelph e testes de Slug.

\section{CARACTERIZAÇÃO DA ÁREA DE ESTUDO Localização}

O município de Rio Claro localiza-se no centro do Estado de São Paulo, na Depressão Periférica Paulista (unidade geomorfológica representada por uma área rebaixada, com altitudes de 500 a 700 metros). É circundado, num raio de aproximadamente $30 \mathrm{~km}$, pelos municípios de Corumbataí e Leme, a norte, Piracicaba e Iracemápolis, a sul, Araras e Santa Gertrudes, a leste, Ipeúna e Itirapina, a oeste.

A UNESP - Campus de Rio Claro está situada na porção sudeste do município de Rio Claro, no bairro Bela Vista (Figura 1).

\footnotetext{
${ }^{1}$ Curso de Pós-Graduação em Geociências e Meio Ambiente - UNESP/Rio Claro - Laboratório de Estudos de Bacias LEBAC (aoliva@rc.unesp.br)

${ }^{2}$ Departamento de Geologia Aplicada - UNESP/Rio Claro - Laboratório de Estudos de Bacias - LEBAC

(chang@rc.unesp.br); (mrchang@rc.unesp.br)
} 


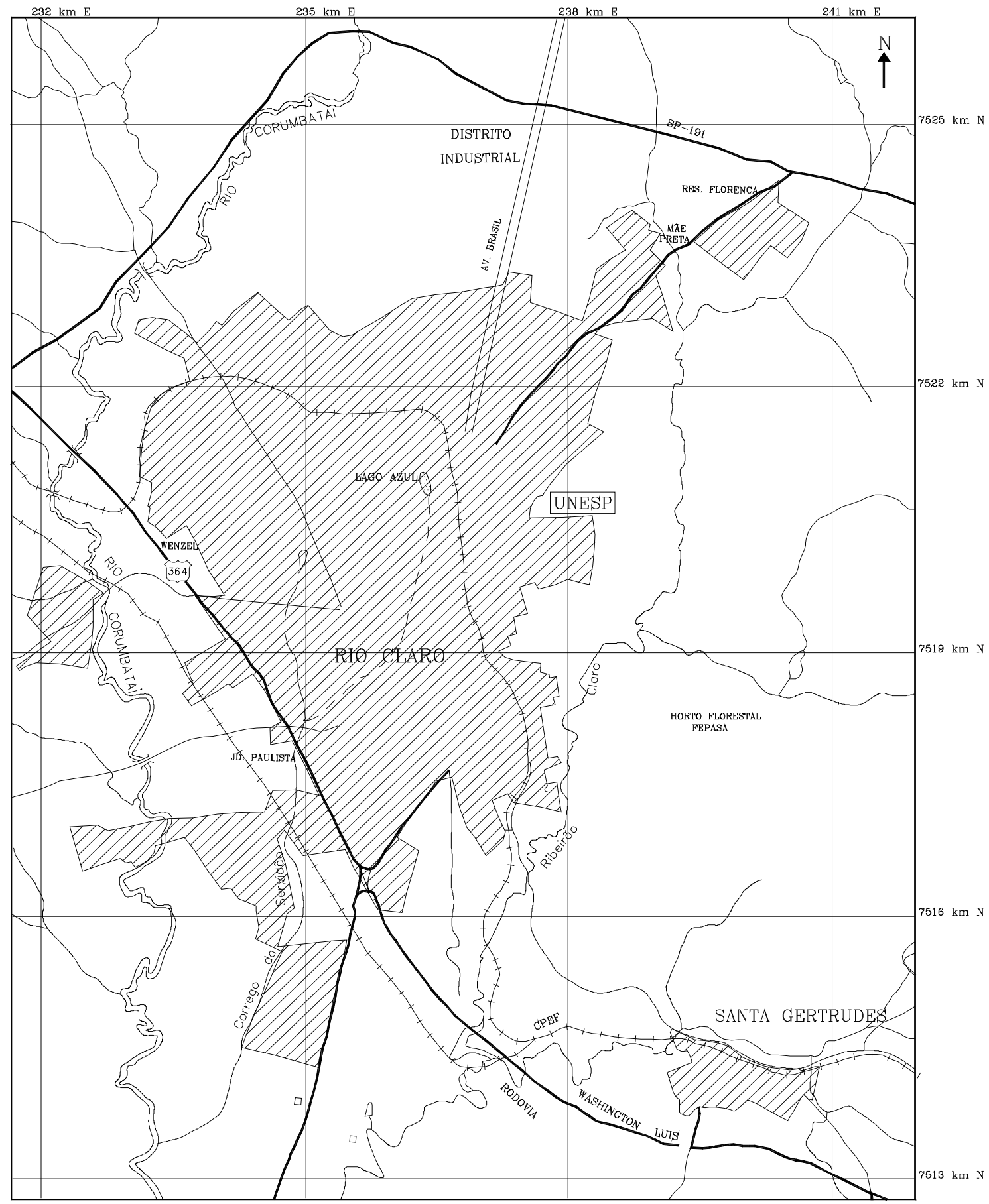

Figura 1 - Mapa de localização do município de Rio Claro Figure 1 - Location of Rio Claro County.

\section{Contexto Geológico Regional}

A área de estudo localiza-se no setor paulista do flanco nordeste da Bacia Sedimentar do Paraná, representada por rochas sedimentares e vulcânicas das eras Paleozóica (Subgrupo Itararé, formações Tatuí, Irati e Corumbataí), Mesozóica (formações Pirambóia, Botucatu e Serra Geral) e Cenozóica (Formação Rio Claro e depósitos recentes).
A Universidade está posicionada sobre os arenitos da Formação Rio Claro, que nesta região apresenta espessura aproximada de 20 metros, seguida de siltitos da Formação Corumbataí, localmente intrudido por diques e sills de diabásio.

A Formação Rio Claro é caracterizada por depósitos neocenozóicos que recobrem extensas áreas no estado de São Paulo. Esses depósitos ocorrem em níveis escalonados na paisagem, 
vinculados a fases de aplainamento. Suas espessuras, em geral pequenas, não ultrapassam 30 metros (FREITAS et al., 1979).

Três níveis topográficos principais, capeados por sedimentos neocenozóicos ocorrem na área da Depressão Periférica e de Cuestas Basálticas próximas a Rio Claro (BJORNBERG; LANDIM, 1966):

1. mais alto, entre 900 e 1000 metros, situado no município de São Carlos;

2. intermediário, entre 800 e 900 metros, correspondente à Serra de Santana e à área da cidade de Itirapina;

3. inferior, entre 600 e 800 metros, sobre o qual se encontra a cidade de Rio Claro.

Os sedimentos neocenozóicos situados no patamar inferior, com espessura máxima de 30 metros, foram formalmente denominados de Formação Rio Claro, por Bjornberg; Landim (1966).

Os depósitos sedimentares atribuídos a esta unidade ocorrem mais extensamente no platô do município de Rio Claro e, de forma mais descontínua, nas proximidades do limite leste da Depressão Periférica, junto ao Planalto Atlântico (ALMEIDA; BARBOSA, 1953).

Fúlfaro; Suguio (1968) identificaram na Formação Rio Claro duas seqüências principais:

1. uma basal, com 20 metros de espessura máxima, composta por uma sucessão de estratos arenosos com intercalações subordinadas de leitos argilosos, interpretada como depósitos de paleocanal fluvial;

2. uma superior, constituída dominantemente por sedimentos argilosos, com brechas intraformacionais e lentes arenosas subordinadas, interpretada como depósitos de planícies de inundação.

A Formação Rio Claro é constituída por quatro litofácies principais (MELO et al., 1997):

1. lamitos de processos gravitacionais (ocorre principalmente próximo aos relevos mais acidentados do limite leste da Depressão Periférica, junto ao Planalto Atlântico);

2. cascalhos e areias de canais e barras fluviais;

3. areias finas de rompimento de diques marginais;

4. argilas de transbordamento em planícies de inundação.

Além dessas quatro litofácies principais, a Formação Rio Claro apresenta um horizonte delgado de conglomerados basal, cuja constituição reflete a contribuição de rochas sedimentares do substrato. Essas litofácies reconhecidas na Formação Rio Claro indicam sedimentação em ambiente fluvial meandrante, no qual se admite baixos gradientes e clima úmido. Quanto às relações estratigráficas, a Formação Rio Claro aparece principalmente sobreposta à Formação Corumbataí (OLIVA, 2002).

Os dados obtidos da descrição das amostras recuperadas durante a perfuração dos poços de monitoramento e de sua análise granulométrica indicam que os arenitos da Formação Rio Claro possuem uma granulometria que varia de areia fina a média.

\section{METODOLOGIA}

A determinação da condutividade hidráulica envolveu etapas de campo e laboratório que consistiram na coleta de amostras para análise petrográfica e na realização de ensaios de permeabilidade para determinação da condutividade hidráulica.

\section{Análise Granulométrica}

Nesta etapa, foram coletadas amostras da Formação Rio Claro recuperadas durante a perfuração de três poços de monitoramento na UNESP - Campus de Rio Claro (Figura 2).

Essas amostras foram submetidas à análise granulométrica (via peneiramento) utilizando-se peneiras com intervalo de 4 a 230 mesh e adotando-se a classificação de Friedman; Sanders (1978).

Posteriormente, amostras foram impregnadas com resina epóxi para confecção de lâminas delgadas utilizadas na análise petrográfica.

\section{Ensaios de Permeabilidade}

Ensaios de permeabilidade são correntemente realizados com a finalidade de determinar a condutividade hidráulica de aqüíferos. Freqüentemente são executados em furos de sondagens, onde são conhecidos, de forma genérica, como "ensaios de infiltração". Com menor frequiência, têm sido também aplicados em poços de inspeção e cavas abertas em solos. Estes ensaios não utilizam sistema de observação da variação das cargas piezométricas nas imediações do furo onde se realiza o ensaio. Por esta razão, são conhecidos como "ensaios pontuais".

Os ensaios de permeabilidade em solos/sedimentos podem ser classificados, conforme a maneira de realização, em ensaios em nível constante e ensaios em nível variável.

Ensaios em nível constante são realizados através da manutenção do nível da água numa posição constante ao longo de toda duração do ensaio, e podendo ser realizados através da introdução de água (ensaios de infiltração) ou da retirada de água (ensaios de bombeamento). 

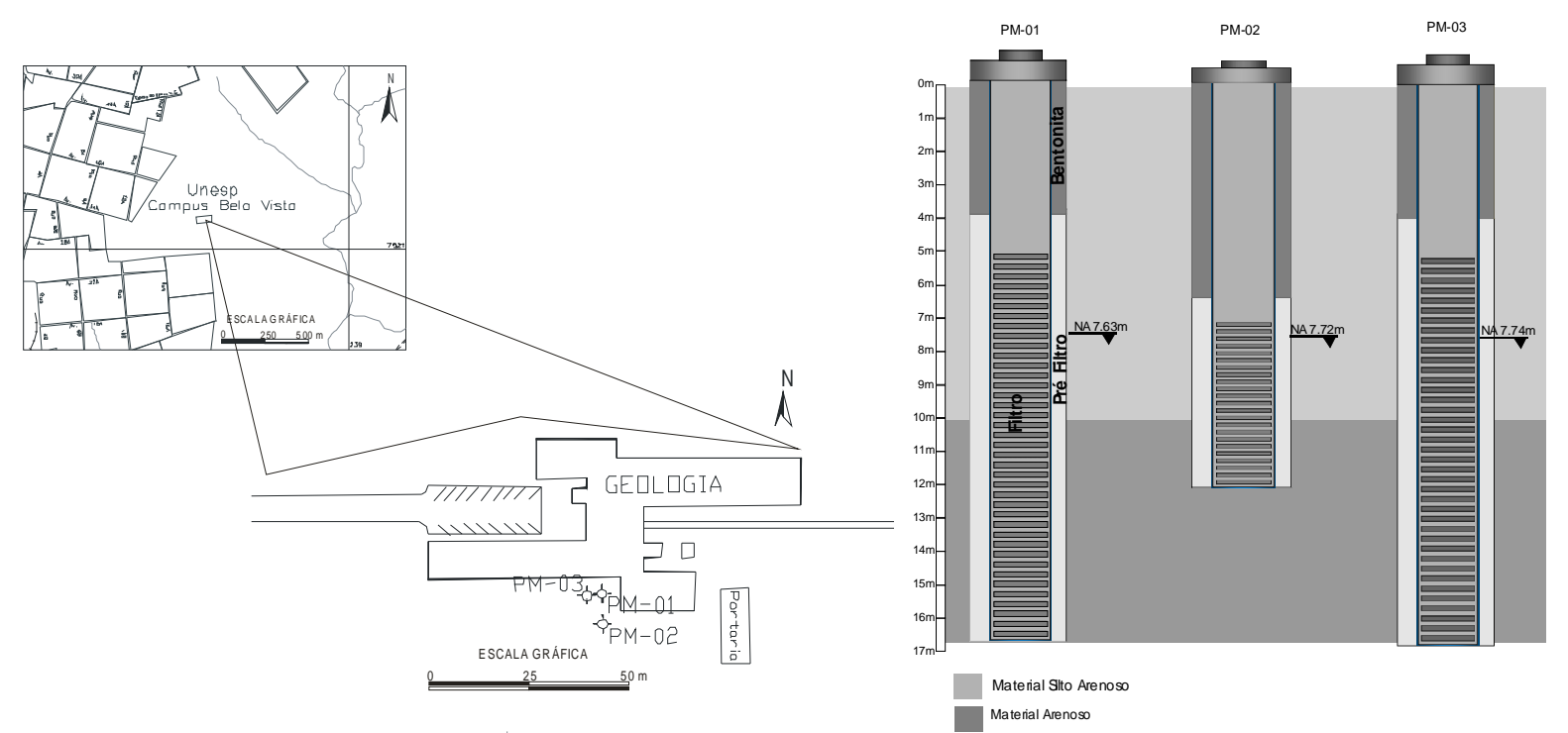

Figura 2 - Localização e perfil esquemático dos poços de monitoramento perfurados na Formação Rio Claro, no Campus de Rio Claro

Figure 2 - Location and schematic profile of the monitoring wells drilled in Rio Claro Formation, in Rio Claro Campus.

Nos ensaios de infiltração, é aplicada uma carga (constante), medindo-se a vazão injetada necessária para manter tal nível constante; nos ensaios de bombeamento, o aqüífero é descarregado, medindo-se a vazão bombeada necessária para manter constante o nível rebaixado.

Nos ensaios em nível variável, o nível da água natural é alterado para uma posição denominada nível inicial do ensaio. A tendência do nível da água voltar à posição original é acompanhada ao longo do tempo de ensaio.

Deve-se considerar que os ensaios realizados nas porções não saturadas dos solos (acima do lençol freático) admitem, obviamente, apenas sua realização por injeção de água (ensaios de "carga").

Neste estudo, foram realizados três tipos de ensaios de permeabilidade que serão descritos a seguir.

\section{Permeâmetro Guelph}

O permeâmetro Guelph, modelo 2800, foi utilizado na determinação expedita da condutividade hidráulica da zona não saturada da Formação Rio Claro in situ. A realização de ensaios à carga constante funciona segundo o princípio do Sifão de Mariotte (Figura 3). O procedimento do ensaio requer, após análise e seleção dos locais a serem ensaiados, a realização de furos a trado com fundo plano.

Quando se estabelece um nível da água (carga hidráulica) constante no interior do furo de trado, origina-se um "bulbo" de saturação da água a partir de sua base (Figura 4).
$\mathrm{O}$ volume da água que infiltra no solo por unidade de tempo (taxa de infiltração) torna-se constante após determinado tempo de estabilização. As características e dimensões deste "bulbo" de saturação da água, uma vez atingida a condição de estabilidade, variam com as características do solo ensaiado.

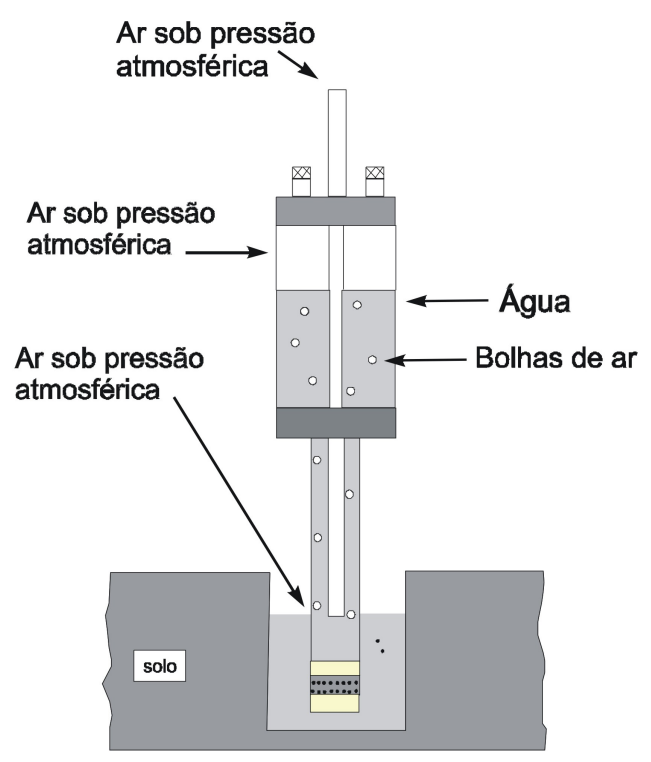

Figura 3 - Funcionamento do Permeâmetro Guelph, segundo o princípio de Sifão de Mariotte (SOIL MOISTURE, 1991).

Figure 3 - Ilustration of Guelph Permeameter, employing the Mariotte Principle (SOIL MOISTURE, 1991).

$\mathrm{O}$ valor da taxa de infiltração, associado às dimensões do furo e à altura da coluna da água no seu interior, permitem o cálculo da condutividade hidráulica in situ, através da seguinte expressão, segundo Soil Moisture Corp. (1991): 
onde:

$$
\begin{gathered}
K=\left[(0,0041)(X)\left(R_{2}\right)-(0,0054)(X)\left(R_{1}\right)\right] \\
K=\left[(0,0041)(Y)\left(R_{2}\right)-(0,0054)(Y)\left(R_{1}\right)\right]
\end{gathered}
$$

$\mathrm{K}$ - condutividade hidráulica, em $\mathrm{cm} / \mathrm{s}$;

R1; R2 - taxas de infiltração estabilizadas correspondentes a $\mathrm{H} 1$ e $\mathrm{H} 2$ respectivamente, em $\mathrm{cm} / \mathrm{s}$

$\mathrm{X} ; \mathrm{Y}$ - constantes correspondentes à área do tubo (reservatório da água) utilizado, em $\mathrm{cm}^{2}$. Nos ensaios de permeabilidade com o Permeâmetro Guelph, utilizou-se ambos reservatórios, interno e externo. Em consequiência disto, a constante empregada nos cálculos foi $\mathrm{X}=35,46 \mathrm{~cm}^{2}$;

0,0041 e 0,0054 - valores adimensionais que podem ser obtidos através da fórmula:

$$
G_{2}=\frac{H_{1} C_{2}}{\pi\left[2 H_{1} H_{2}\left(H_{2}-H_{1}\right)+a^{2}\left(H_{1} C_{2}-H_{2} C_{1}\right)\right]}
$$

Sendo,

$$
G_{1}=G_{2} \frac{\left[H_{2} C_{1}\right]}{\left[H_{1} C_{2}\right]},
$$

onde:

H1 e H2 - altura d’água no furo para a primeira $(5 \mathrm{~cm})$ e a segunda $(10 \mathrm{~cm})$ medidas, respectivamente;

C - fator que depende da relação H/a; a - raio do furo $(\mathrm{cm})$.

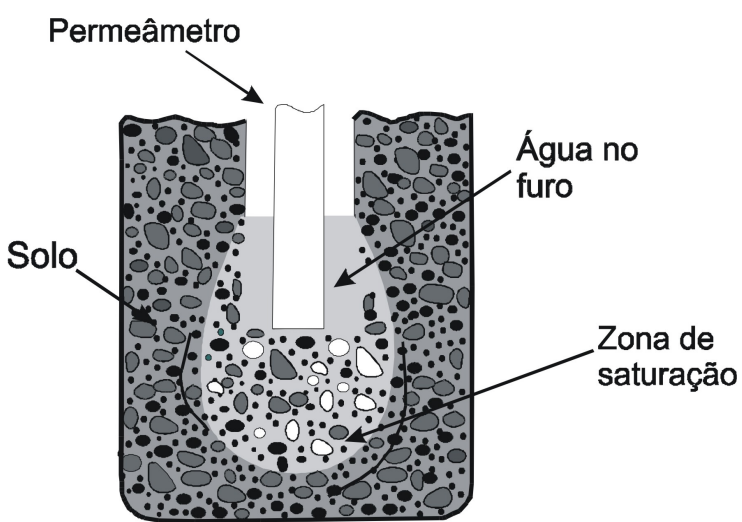

Figura 4 - Bulbo de saturação de água no solo (SOIL MOISTURE, 1991).

Figure 4 - Water saturation bulb in soil (SOIL MOISTURE, 1991).

\section{Teste de Slug}

O ensaio conhecido como teste de slug é um ensaio de permeabilidade, realizado em nível variável (zona saturada), em que é aplicada uma carga ou descarga através da introdução ou remoção súbita de um volume (sólido cilíndrico de volume conhecido) dentro do poço, de forma que o nível d'água (NA) seja elevado ou rebaixado instantaneamente. A estabilização desse nível pode ser tão rápida que muitas vezes só é possível acompanhá-lo através de transdutores de pressão.

Quando o volume é removido, o teste é conhecido como "bail test" e, quando adicionado, "slug test" (Figura 5). Este volume deslocado é igual à adição ou à remoção de água do aqüífero.

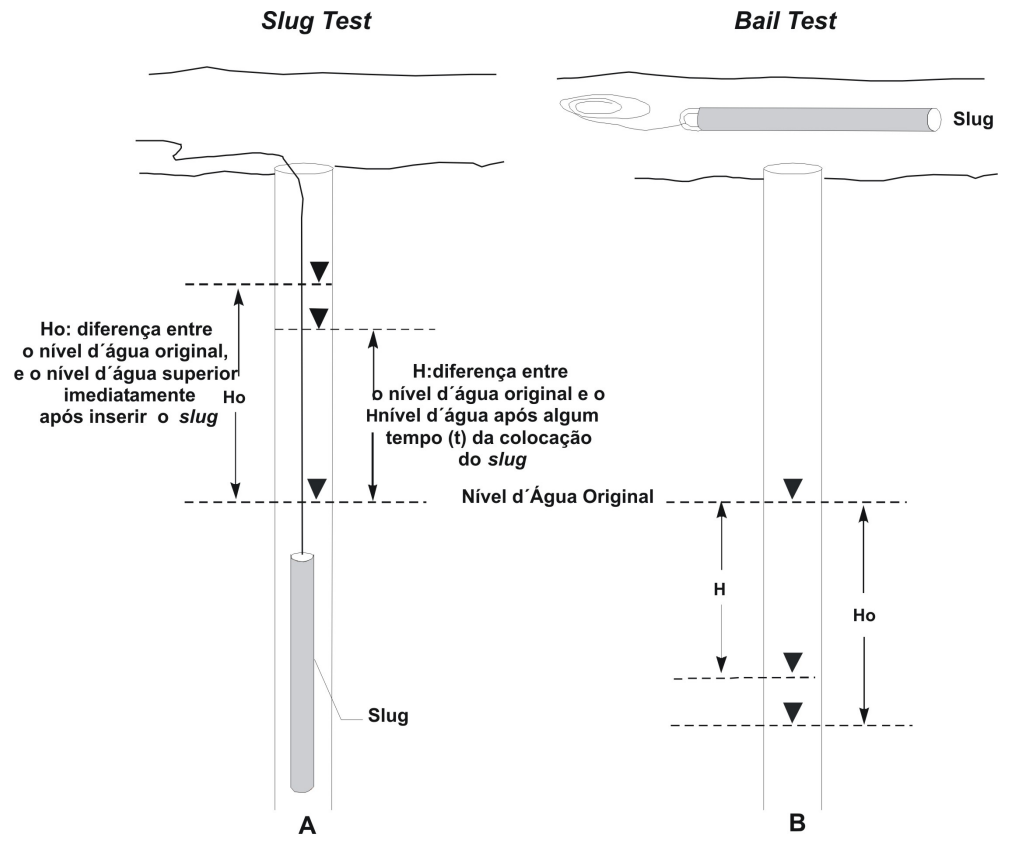

Figura 5 - (A) Slug Test e (B) Bail Test.

Figure 5 - (A) Slug Test and (B) Bail Test. 
$\mathrm{O}$ resultado do monitoramento da posição do nível da água (NA) é uma curva de rebaixamento ou recuperação do NA, com o tempo. Desta curva são extraídos os parâmetros que, juntamente com as características geométricas do poço, fornecem o valor de condutividade hidráulica (DAWSON; JONATHAN, 1991).

$\mathrm{A}$ interpretação do nível da água $\mathrm{x}$ tempo para o bail test e o slug test pode ser obtida pelos métodos de Hvorslev (1951) e Bouwer; Rice (1976).

\section{Hvorslev (1951)}

A determinação da condutividade hidráulica pelo método de Hvorslev (Figura 6) é obtida através da seguinte fórmula:

$$
K=\frac{r^{2} \ln \left(L_{e} / R\right)}{2 L_{e} T_{0}}, \text { onde: }
$$

$\mathrm{K}$ - condutividade hidráulica $(\mathrm{cm} / \mathrm{s})$;

$\mathrm{r}$ - raio do revestimento $(\mathrm{cm})$;

$\mathrm{R}$ - raio do poço $(\mathrm{cm})$;

Le - comprimento do filtro $(\mathrm{cm})$;

To - tempo que leva para o nível da água cair a $37 \%$ da posição inicial (s).

\section{Bouwer e Rice (1976)}

A determinação da condutividade hidráulica pelo método de bouwer e rice (figura 7) utiliza as seguintes equações:

$$
K=\frac{r_{c}^{2} \ln \left(R_{e} / R\right)}{2 L e} \frac{1}{t} \ln \left(\frac{H_{0}}{H_{t}}\right) \quad \mathrm{e}
$$

$$
\ln \frac{R_{e}}{R}=\left[\frac{1.1}{1 n\left(L_{w} / R\right)}+\frac{A+B \ln \left[\left(h-L_{w}\right) / R\right]}{L_{e} / R}\right]^{-1}
$$

quando, $\mathbf{L w}$ for igual a $\mathbf{h}$,

$$
\ln \frac{R_{e}}{R}=\left[\frac{1.1}{1 n\left(L_{w} / R\right)}+\frac{C}{L_{e} / R}\right]^{-1}
$$

onde:

$\mathrm{K}$ - condutividade hidráulica $(\mathrm{cm} / \mathrm{s})$;

rc - raio do revestimento $(\mathrm{cm})$;

$\mathrm{R}$ - raio do poço $(\mathrm{cm})$;

Re - distância radial efetiva em que a carga é dissipada $(\mathrm{cm})$; Le - comprimento do filtro ou intervalo por onde a água se infiltra $(\mathrm{cm})$;

Lw - distância da superfície da água à base do filtro $(\mathrm{cm})$;

Ho - rebaixamento no tempo $\mathrm{t}=0(\mathrm{~cm})$;

$\mathrm{Ht}$ - rebaixamento no tempo $\mathrm{t}=\mathrm{t}(\mathrm{cm})$;

$\mathrm{T}$ - tempo decorrido após $\mathrm{H}=0$ (s);

A, B e C - valores adimensionais, obtidos através da relação $\mathrm{L}_{\mathrm{e}} / \mathrm{R}$.

$\mathrm{O}$ valor do raio do revestimento $r_{c}$ ainda passa por uma correção devido à porosidade do pré-filtro, através da fórmula Bouwer (1989):

$$
r_{c}^{\prime}=\sqrt{(1-n) r_{c}^{2}+n R}
$$

onde,

$\mathrm{r}_{\mathrm{c}}$ - raio do revestimento já corrigido $(\mathrm{cm})$;

$r_{c}$ - raio do revestimento original $(\mathrm{cm})$;

$\mathrm{n}$ - porosidade do pré-filtro (entre 0 e 1 );

$\mathrm{R}$ - raio do poço $(\mathrm{cm})$.

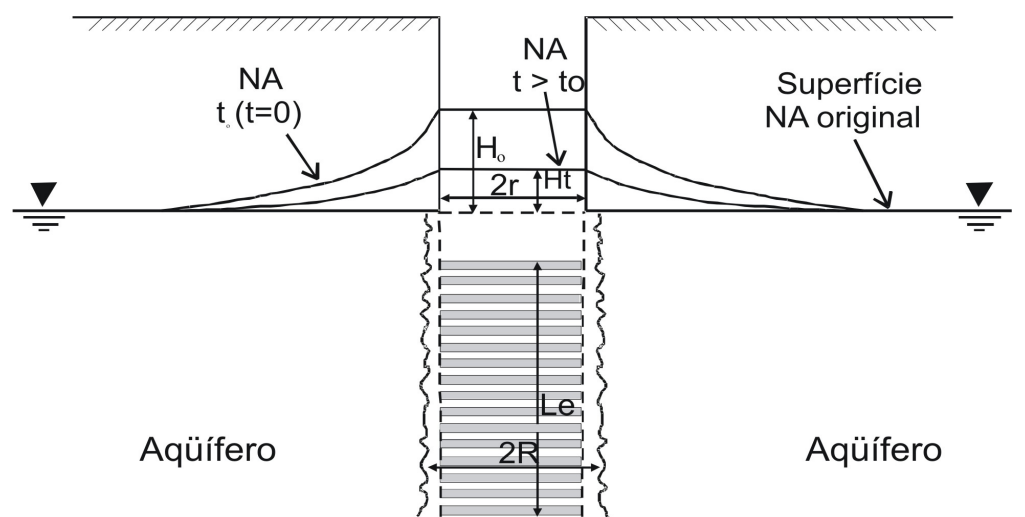

Impermeável

Figura 6 - Desenho esquemático do teste de slug com os parâmetros geométricos, necessários para estimar a condutividade hidráulica pelo método de Hvorslev (1951).

Figure 6 - Schematical drawing of slug test with geometric parameters used in the determination of hydraulic conductivity by Hvorslev method (1951). 


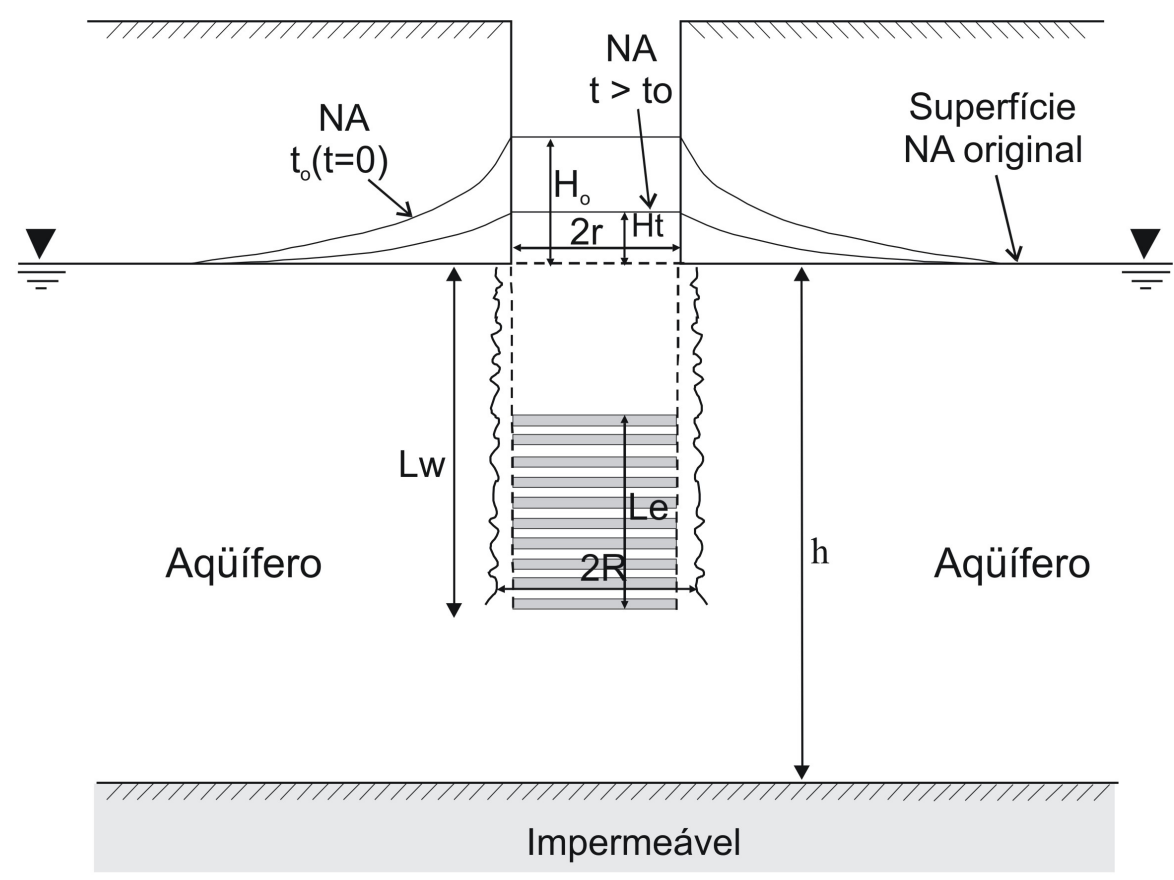

Figura 7 - Desenho esquemático do teste de slug com os parâmetros geométricos, necessários para estimar a condutividade hidráulica pelo método de Bouwer e Rice (1976).

Figure 7 - Schematical drawing of slug test with geometric parameters used in the determination of hydraulic conductivity by Bouwer and Rice method (1976).

\section{Análise Granulométrica}

Além desses ensaios, a condutividade hidráulica também foi determinada utilizando parâmetros obtidos na curva granulométrica dos sedimentos arenosos da Formação Rio Claro, através dos métodos de Hazen (1911) e Shepherd (1989).

O método de Hazen é aplicado a sedimentos em que o diâmetro efetivo do grão $\left(\mathrm{d}_{10}\right)$ situa-se, aproximadamente, entre 0,1 e 3,0 $\mathrm{mm}$. A fórmula aplicada ao método de Hazen é:

$$
K=C\left(d_{10}\right)^{2}
$$

onde,

$\mathrm{K}$ - condutividade hidráulica $(\mathrm{cm} / \mathrm{s})$;

$\mathrm{d}_{10}$ - diâmetro efetivo do grão $(\mathrm{cm})$;

$\mathrm{C}$ - valor adimensional que pode ser obtido experimentalmente; areias finas, como as da Formação Rio Claro, possuem um valor aproximado de 60 .

O método de Shepherd considera que a condutividade hidráulica está relacionada ao diâmetro e à maturidade dos grãos e estabelece uma fórmula geral do tipo:

$$
K=C d_{50}^{j}
$$

onde,

C - fator de ajuste, obtido experimentalmente;

$\mathrm{d}_{50}$ - diâmetro efetivo do grão $(\mathrm{mm})$;

$\mathrm{j}$ - expoente obtido experimentalmente, que leva em consideração a textura dos sedimentos.

$\mathrm{O}$ fator de ajuste $\mathbf{C}$ e o expoente $\mathbf{j}$ possuem valores altos para sedimentos maturos, e decaem para sedimentos imaturos.

Shepherd (1989) utilizou vários dados para desenvolver e produzir um gráfico que permite determinar a condutividade hidráulica para grãos de diâmetros intermediários, de diferentes tipos de sedimentos (Figura 8).

No caso da Formação Rio Claro, para o cálculo de condutividade hidráulica segundo o método de Shepherd, utilizou-se um valor $\mathrm{C}=100$ e o expoente $\mathrm{j}=1,5$, correspondendo a sedimentos consolidados.

\section{AQÜÍFERO RIO CLARO}

Segundo o DAEE (1981), a cidade de Rio Claro está assentada sobre os grupos Passa Dois e Tubarão e intrusivas básicas.

As zonas aquíferas que ocorrem no Grupo Passa Dois armazenam água tanto por porosidade de interstícios como de fissuras, dependendo da litologia e situação estrutural local. 


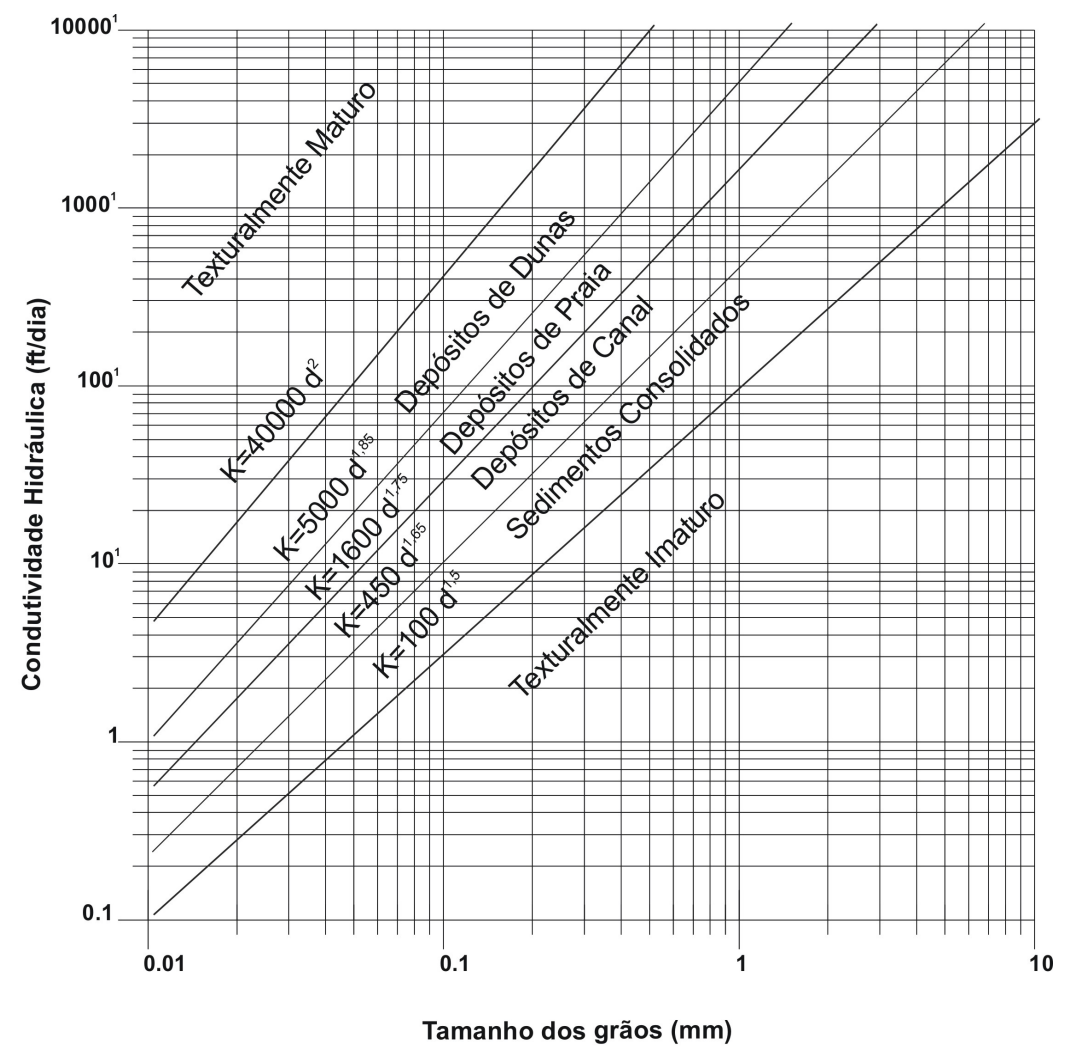

Figura 8 - Gráfico mostrando a relação da condutividade hidráulica com o diâmetro dos grãos de sedimentos texturalmente diferentes (Fetter, 1988).

Figure 8 - Graph showing the relationship of hydraulic conductivity to mean grain size diameter for sediments of different textures (Fetter, 1988).

Segundo DAEE (1981), a capacidade específica nas zonas aqüíferas do Grupo Passa Dois variam de 0,05 a $1,25 \mathrm{~m}^{3} / \mathrm{h} / \mathrm{m}$ e a transmissividade está abaixo de $10 \mathrm{~m}^{2} /$ dia.

No município de Rio Claro, ocorrem dois sistemas principais de águas subterrâneas. O primeiro consiste em um aqüífero livre pouco profundo, com vazão entre $17 \mathrm{~m}^{3} / \mathrm{h}$ e $25 \mathrm{~m}^{3} / \mathrm{h}$, constituído pelos materiais pouco consolidados da Formação Rio Claro, tema do presente trabalho. O segundo sistema compreende rochas do Grupo Tubarão, mais especificamente da Formação Tatuí e do Subgrupo Itararé, que constitui um aqüífero confinado, com profundidades em torno de $200 \mathrm{~m}$ e vazão entre $20 \mathrm{~m}^{3} / \mathrm{h}$ e $37 \mathrm{~m}^{3} / \mathrm{h}$.

Além desses sistemas aqüíferos ocorre também ampla distribuição, na região, de rochas intrusivas básicas, comumente sob a forma de diques e sills. Esses corpos profundos de diabásio podem conter água em suas fraturas, exibindo vazões entre $5 \mathrm{~m}^{3} / \mathrm{h}$ e $30 \mathrm{~m}^{3} / \mathrm{h}$.

\section{Arcabouço Mineralógico e Textural do Aqüífero Rio Claro}

Através da descrição de lâminas delgadas, observou-se que o principal constituinte detrítico do arcabouço dos arenitos da Formação Rio Claro é quartzo.

Os feldspatos, que não aparecem nas amostras descritas, provavelmente sofreram diagênese, lixiviação e transformação para argilominerais, juntando-se à matriz argilosa e compondo uma pseudomatriz.

A matriz é constituída por cutículas de argila, cuja composição é caulinítica, envolvendo os cristais de quartzo e preenchendo os poros.

Os fragmentos líticos não estão bem definidos, confundindo-se com a matriz de infiltração (caulinita) e com feldspatos bastante alterados. Por esta razão, a matriz pode conter fragmentos líticos, principalmente os sedimentares.

Os arenitos da Formação Rio Claro, de maneira geral, possuem granulometria que varia de areia fina à média (Figura 9). Alguns desses arenitos apresentam alto teor de argilas e outros são conglomeráticos. Seus grãos são subarredondados a arredondados. 

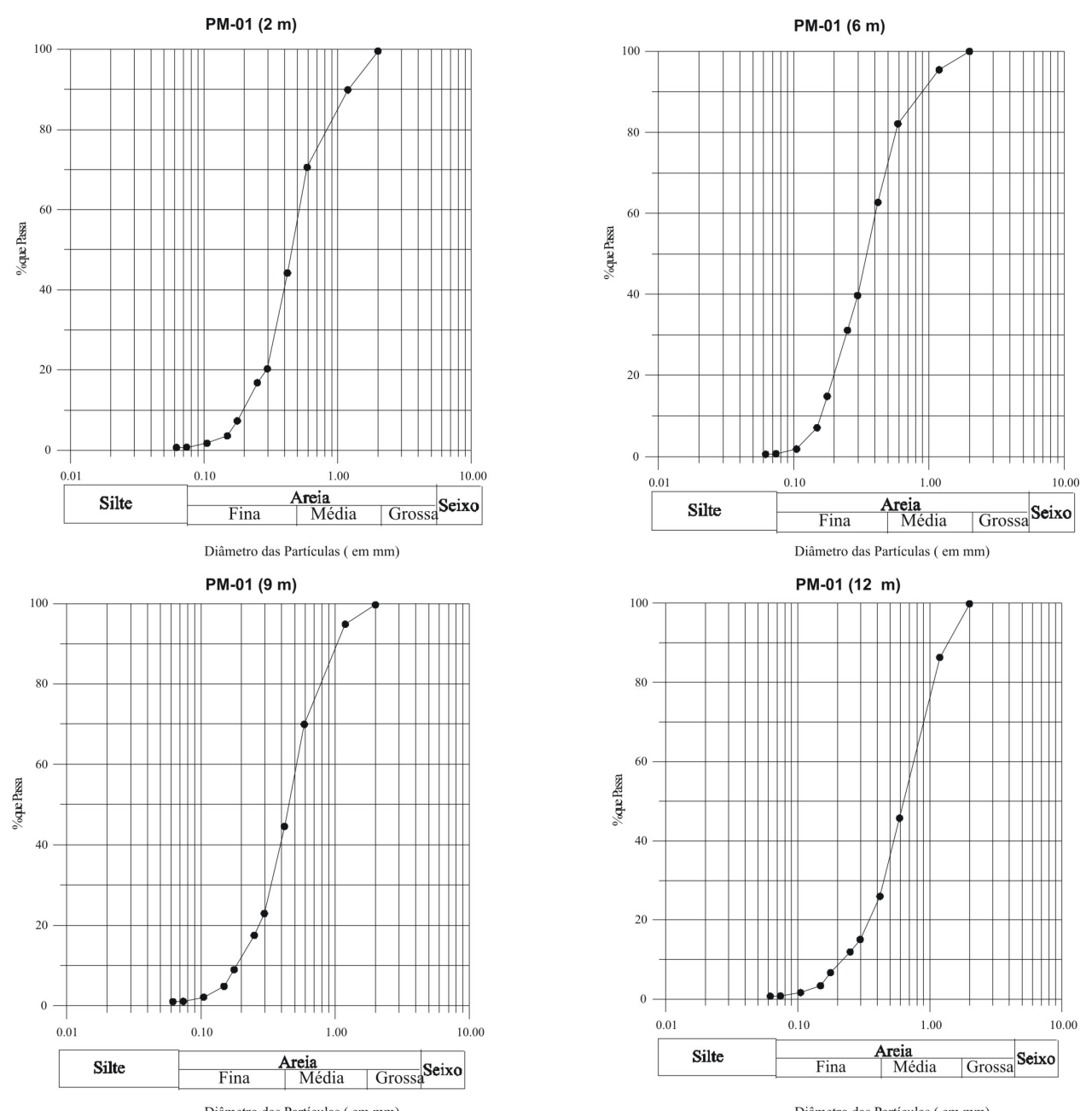

Diâmetro das Partículas ( $\mathrm{em} \mathrm{mm}$ )

Diâmetro das Partículas ( $\mathrm{em} \mathrm{mm}$ )
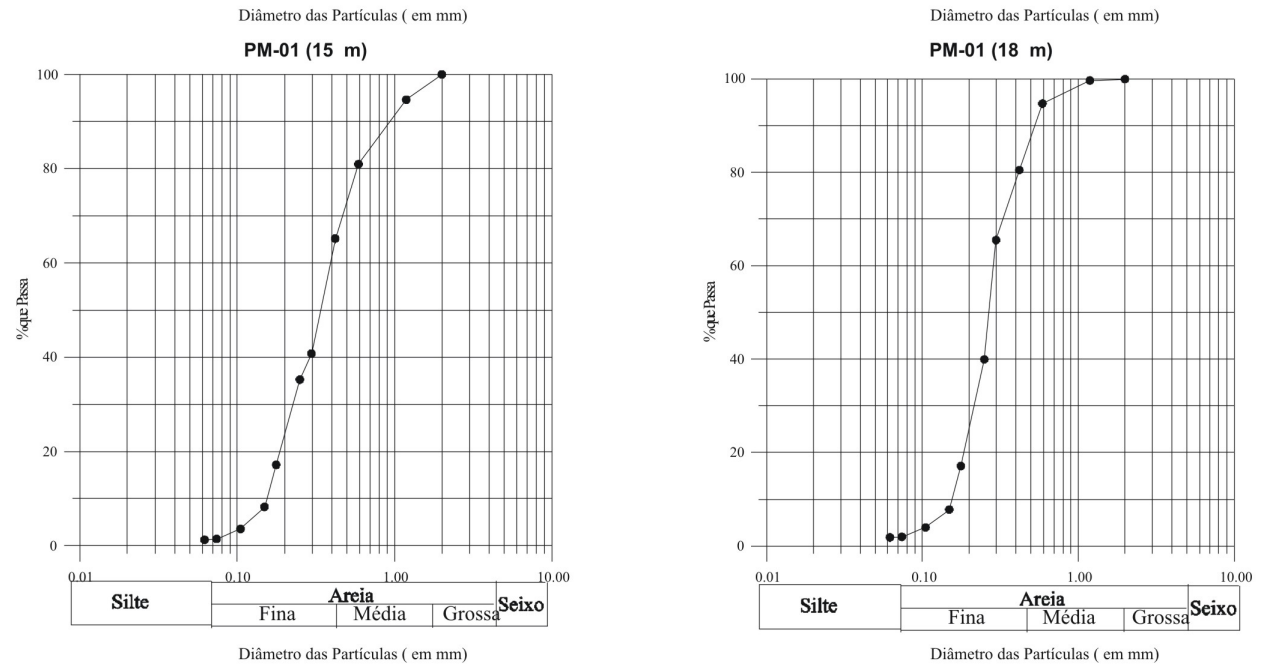

Figura 9 - Granulometria das amostras recuperadas durante a perfuração do poço de monitoramento PM - 01 . Figure 9 - Grain size analyses of the samples recovered from the monitoring well PM-01.

Segundo o esquema de classificação proposto por Folk (1968), considerando quartzo, feldspato e fragmentos líticos, os arenitos da Formação Rio Claro são classificados como quartzo-arenito. No entanto, devido à grande quantidade de matriz, estes são melhor classificados como quartzo-arenito imaturo.
Condutividade Hidráulica do Aqǘfero Rio Claro Análise Granulométrica

A determinação de condutividade hidráulica, utilizando a análise granulométrica, é aplicada com freqüência em sedimentos inconsolidados, para os quais se obtém uma boa resposta. Os sedimentos da Formação Rio Claro não podem 
ser considerados totalmente inconsolidados mas, por possuírem pouco cimento, forneceram excelentes resultados.

Os dois métodos utilizados neste estudo foram Hazen (1911) e Shepherd (1989). O método de Hazen foi utilizado porque os grãos das amostras analisadas da Formação Rio Claro possuem diâmetro efetivo $\mathrm{d}_{10}$ entre 0,1 e $3 \mathrm{~mm}$.

No método de Shepherd, que incorpora parâmetros sedimentológicos, a determinação de condutividade hidráulica foi efetuada considerando os sedimentos da Formação Rio Claro como consolidados.

As amostras recuperadas durante a perfuração do poço de monitoramento $\mathrm{PM}-01$, na UNESP - Campus de Rio Claro, foram utilizadas para o cálculo da condutividade hidráulica pelos métodos de Hazen e de Shepherd. Os resultados mostraram-se coerentes com a variação da granulometria e são apresentados na Tabela 1 e na Figura 10.

Os valores de condutividade hidráulica obtidos pelo método de Hazen mostraram-se superestimados, apresentando pouca variação. Já os valores obtidos pelo método de Shepherd mostraram-se mais sensíveis à variação textural.

Por exemplo, na profundidade de 2 metros, as amostras coletadas são descritas como sedimentos silto-arenosos, e a condutividade hidráulica obtida foi de $9,6 \times 10^{-3} \mathrm{~cm} / \mathrm{s}$. Já no intervalo de 2 a 3 metros, os sedimentos são mais arenosos, fornecendo valores de condutividade de $1,2 \times 10^{-2} \mathrm{~cm} / \mathrm{s}$. Abaixo deste intervalo, níveis mais siltosos intercalados por níveis mais arenosos apresentam valores de condutividade hidráulica alternando entre $5 \times 10^{-3}$ e $1,2 \times 10^{-2}$ $\mathrm{cm} / \mathrm{s}$.

Os valores de condutividade hidráulica obtidos pelo método de Hazen mostraram-se superestimados, indicando baixa sensibilidade do método.

\section{Método Guelph}

Foi empregado o Permeâmetro Guelph em nove furos de sondagens, de aproximadamente 1 $\mathrm{m}$ de profundidade, em uma malha de $10 \mathrm{~m}$ x 10 $\mathrm{m}$ ao redor dos poços de monitoramento citados anteriormente (Figura 11).

Os resultados de condutividade hidráulica obtidos através desse método forneceram valores entre $8 \times 10^{-4} \mathrm{~cm} / \mathrm{s}$ e $4,9 \times 10^{-3} \mathrm{~cm} / \mathrm{s}$, onde a textura dos solos/sedimentos variaram de arenosos a siltosos, mostrando uma pequena variação faciológica (Tabela 2, Figura 12).

\section{Testes de Slug}

Foram realizados testes de slug nos três poços de monitoramento, utilizando um sólido constituído por um tubo de PVC de 1" de diâmetro e de $2 \mathrm{~m}$ de comprimento. A medição do nível da água (NA) foi efetuada com um transdutor de pressão marca DRUCK, acoplado a um notebook. A leitura e o armazenamento dos níveis foram efetuados automaticamente, utilizando o software WinSlug ${ }^{\circledR} \quad$ (CHANG; CARRIER, 2000), desenvolvido em laboratórios da Unesp.

Os métodos utilizados no presente estudo para interpretar os dados de testes de slug foram os de Hvorslev e de Bouwer e Rice (Figura 13), com os parâmetros construtivos e os resultados listados nas Tabelas 3 e 4.

As variações nos valores de condutividade refletem as variações faciológicas dos locais ensaiados. A menor condutividade obtida no PM - 02 deve-se à ausência de níveis mais arenosos, encontrados no PM - 01, em profundidades superiores a 12 metros.

A diferença de condutividade observada nos poços $\mathrm{PM}$ - 01 e PM - 03, que possuem a mesma profundidade $(17,5 \mathrm{~m})$, pode estar relacionada ao grau de desenvolvimento dos poços, executado após perfuração e instalação, ou à variação faciológica, muito comum em sedimentos fluviais, como é o caso da Formação Rio Claro. $\mathrm{O}$ poço $\mathrm{PM}$ - 01 foi desenvolvido, utilizando compressor de ar, por um total de 20 horas, durante 4 dias alternados. Já o PM - 03, onde encontra-se instalado um transdutor para monitoramento, foi desenvolvido somente por poucas horas, anteriormente à instalação do transdutor.

\section{DISCUSSÃO DOS DADOS DE CONDUTIVIDADE HIDRÁULICA}

Os resultados de análise granulométrica tratados por meio dos métodos de Hazen e Shepherd são aqui comparados com os resultados obtidos pelos testes de slug e método Guelph.

A comparação direta dos valores de condutividade hidráulica, obtidos pelo método Guelph (zona não-saturada) e testes de slug (zona saturada), não se aplica, pois tratam-se de ensaios realizados em diferentes zonas de saturação, onde o comportamento hidrodinâmico é distinto.

\section{Granulometria x Testes de Slug}

Os dois métodos para a determinação da condutividade hidráulica, utilizando a análise granulométrica, apresentaram bons resultados. 
Tabela 1 - Valores de condutividade hidráulica das amostras coletadas durante a perfuração do poço de monitoramento PM - 01, no Campus da Unesp de Rio Claro, obtidos através dos métodos de Hazen e Shepherd.

Table 1 - Hydraulic conductivity values obtained from samples collected from the monitoring well PM-01, drilled in Rio Claro Campus - Unesp, determined by Hazen and Shepherd methods.

\begin{tabular}{|c|c|c|}
\hline \multirow{2}{*}{$\begin{array}{c}\text { Amostras } \\
\text { Profundidade } \\
(\mathrm{m})\end{array}$} & \multicolumn{2}{|c|}{$\begin{array}{c}\begin{array}{c}\text { Condutividade Hidráulica } \\
(\mathrm{cm} / \mathrm{s})\end{array} \\
\end{array}$} \\
\hline & Método de Hazen & Método de Shepherd \\
\hline 2 & $2,4 \times 10^{-2}$ & $9,6 \times 10^{-3}$ \\
\hline 3 & $2,4 \times 10^{-2}$ & $1,1 \times 10^{-2}$ \\
\hline 3,5 & $1,5 \times 10^{-2}$ & $1,2 \times 10^{-2}$ \\
\hline 4 & $1,9 \times 10^{-2}$ & $8,9 \times 10^{-3}$ \\
\hline 4,5 & $1,9 \times 10^{-2}$ & $8,6 \times 10^{-3}$ \\
\hline 5 & $1,7 \times 10^{-2}$ & $8,9 \times 10^{-3}$ \\
\hline 5,5 & $1,7 \times 10^{-2}$ & $7,9 \times 10^{-3}$ \\
\hline 6 & $1,7 \times 10^{-2}$ & $7,3 \times 10^{-3}$ \\
\hline 6,5 & $1,7 \times 10^{-2}$ & $7,3 \times 10^{-3}$ \\
\hline 7 & $1,7 \times 10^{-2}$ & $7,3 \times 10^{-3}$ \\
\hline 7,5 & $1,7 \times 10^{-2}$ & $7,3 \times 10^{-3}$ \\
\hline 8 & $1,9 \times 10^{-2}$ & $8,6 \times 10^{-3}$ \\
\hline 8,5 & $1,9 \times 10^{-2}$ & $8,6 \times 10^{-3}$ \\
\hline 9 & $1,9 \times 10^{-2}$ & $8,6 \times 10^{-3}$ \\
\hline 9,5 & $1,9 \times 10^{-2}$ & $8,6 \times 10^{-3}$ \\
\hline 10 & $1,3 \times 10^{-2}$ & $1,0 \times 10^{-2}$ \\
\hline 10,5 & $1,3 \times 10^{-2}$ & $1,0 \times 10^{-2}$ \\
\hline 11 & $1,5 \times 10^{-2}$ & $8,6 \times 10^{-3}$ \\
\hline 12 & $2,6 \times 10^{-2}$ & $1,7 \times 10^{-2}$ \\
\hline 12,5 & $1,9 \times 10^{-2}$ & $1,2 \times 10^{-2}$ \\
\hline 13 & $7,3 \times 10^{-3}$ & $7,3 \times 10^{-3}$ \\
\hline 13,5 & $7,3 \times 10^{-3}$ & $7,3 \times 10^{-3}$ \\
\hline 16,5 & $1,5 \times 10^{-2}$ & $7,3 \times 10^{-3}$ \\
\hline 18 & $1,5 \times 10^{-2}$ & $5,2 \times 10^{-3}$ \\
\hline
\end{tabular}

\section{METODO DE HAZEN X MÉTODO DE SHEPHERD}

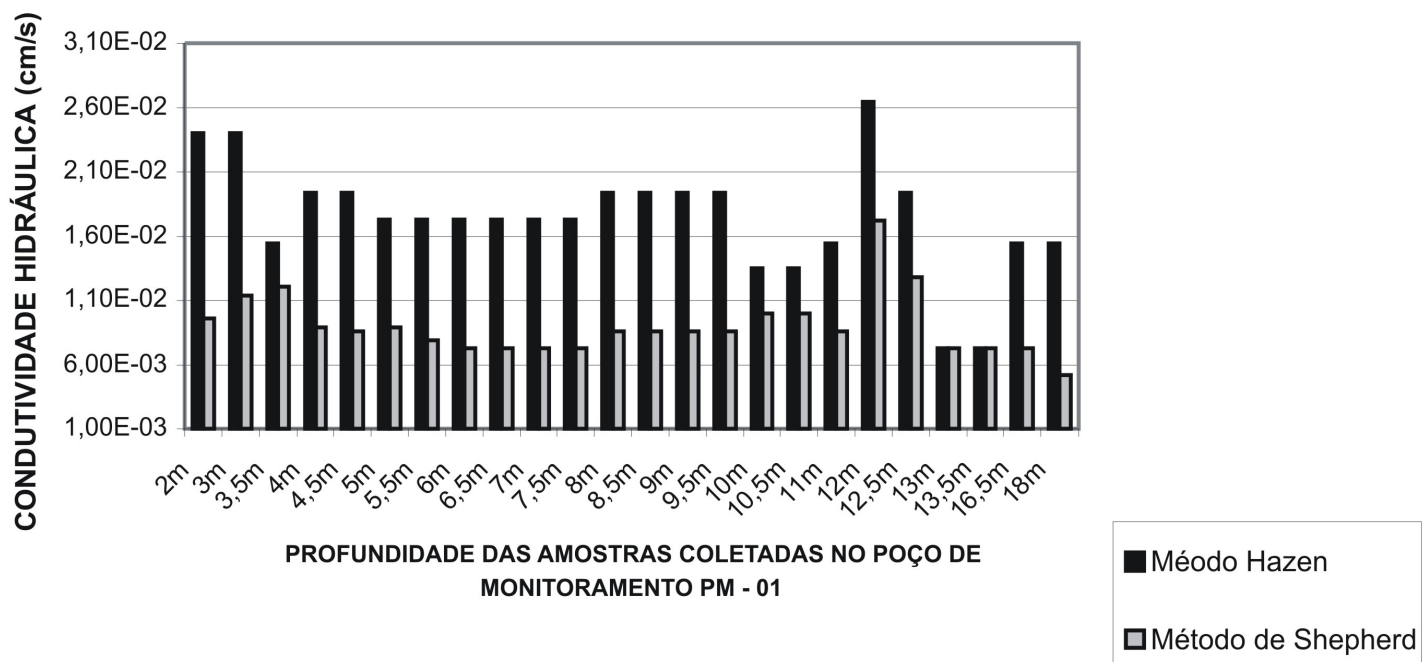

Figura 10 - Gráfico de barras comparando valores de condutividade hidráulica obtidos através dos métodos de Hazen e de Shepherd, em amostras recuperadas durante a perfuração do poço de monitoramento PM-01.

Figure 10 - Bar chart comparing values of hydraulic conductivity determined by Hazen and Shepherd methods from samples recovered from the monitoring well PM-O1. 
Determinação da condutividade hidráulica da Formação Rio Claro:

análise comparativa através de análise granulométrica. e ensaios com permeâmetro guelph e testes de slug

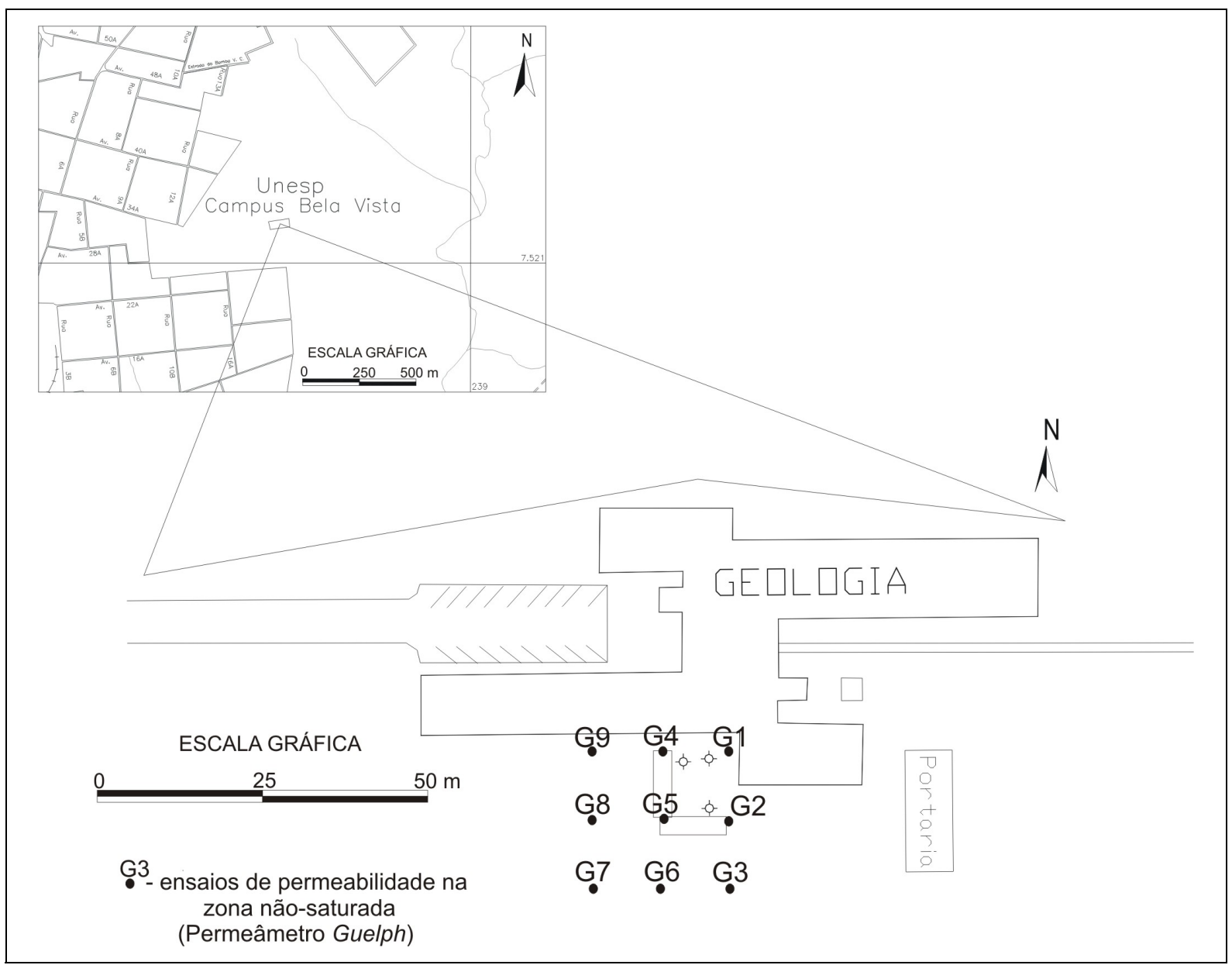

Figura 11 - Localização dos furos de sondagem onde foi empregado o Permeâmetro Guelph.

Figure 11 - Location of hydraulic conductivity determination using Guelph Permeameter.

Tabela 2 - Valores de condutividade hidráulica obtidos através do Permeâmetro Guelph.

Table 2 - Hydraulic conductivity values determined using Guelph Permeameter.

\begin{tabular}{c|c}
\hline \multirow{2}{*}{ Ensaio } & $\begin{array}{c}\text { Condutividade Hidráulica } \\
(\mathbf{c m} / \mathbf{s})\end{array}$ \\
\cline { 2 - 2 } & $\begin{array}{c}\text { Permeâmetro Guelph } \\
\text { G1 }\end{array}$ \\
\hline G2 & $2 \times 10^{-3}$ \\
\hline G3 & $2,3 \times 10^{-3}$ \\
\hline G4 & $2 \times 10^{-3}$ \\
\hline G5 & $4,9 \times 10^{-3}$ \\
\hline G6 & $3 \times 10^{-3}$ \\
\hline G7 & $1 \times 10^{-3}$ \\
\hline G8 & $8 \times 10^{-4}$ \\
\hline G9 & $9 \times 10^{-4}$ \\
\hline & $3,7 \times 10^{-3}$ \\
\hline
\end{tabular}




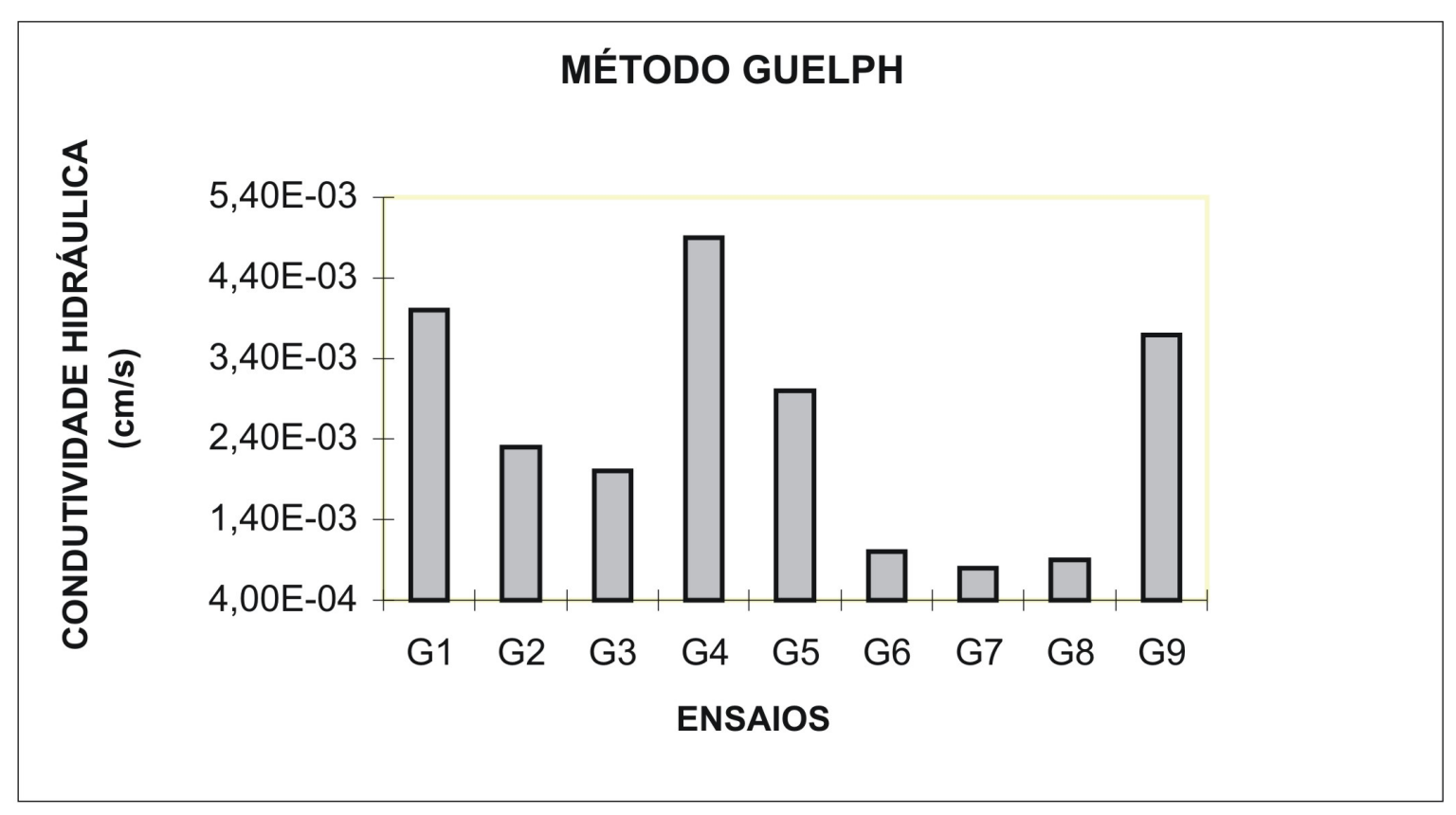

Figura 12 - Gráfico de barras ilustrando a distribuição dos valores de condutividade hidráulica obtidos utilizando o método Guelph.

Figure 12 - Bar chart ilustrating the distribution of hydraulic conductivity values determined using Guelph Permeameter.

Tabela 3 - Profundidade do nível da água, e dados construtivos dos poços de monitoramento.

Table 3 - Depth of water level and well log data of the monitoring wells.

\begin{tabular}{c|c|c|c|c|c}
\hline & $\begin{array}{c}\text { Profundidade } \\
\text { do N.A. } \\
(\mathbf{c m})\end{array}$ & $\begin{array}{c}\text { Profundidade } \\
\text { do Poço } \\
(\mathbf{c m})\end{array}$ & $\begin{array}{c}\text { Raio do } \\
\text { Revestimento } \\
(\mathbf{c m})\end{array}$ & $\begin{array}{c}\text { Raio } \\
\text { do Poço } \\
(\mathbf{c m})\end{array}$ & $\begin{array}{c}\text { Comprimento } \\
\text { Total do Filtro } \\
(\mathbf{c m})\end{array}$ \\
\hline PM-01 & 753 & 1750 & 2,54 & 7,50 & 987,0 \\
\hline PM-02 & 772 & 1180 & 2,54 & 7,50 & 408,0 \\
\hline PM-03 & 774 & 1750 & 2,54 & 7,50 & 976,0 \\
\hline
\end{tabular}

Tabela 4 - Valores de condutividade hidráulica obtidos através de testes de slug - métodos de Hvorslev e Bouwer; Rice.

Table 4 - Hydraulic conductivity values determined by slug test - Hvorslev and Bouwer; Rice methods.

\begin{tabular}{c|c|c}
\hline \multirow{2}{*}{ Ensaio } & \multicolumn{2}{|c}{$\begin{array}{c}\text { Condutividade Hidráulica } \\
(\mathbf{c m} / \mathbf{s})\end{array}$} \\
\cline { 2 - 3 } & método de Hvorslev & método de Bouwer; Rice \\
\hline PM - 01 & $7,71 \times 10^{-3}$ & $1,74 \times 10^{-2}$ \\
\hline PM - 02 & $2,57 \times 10^{-4}$ & $5,15 \times 10^{-4}$ \\
\hline PM - 03 & $2,79 \times 10^{-3}$ & $6,33 \times 10^{-3}$ \\
\hline
\end{tabular}



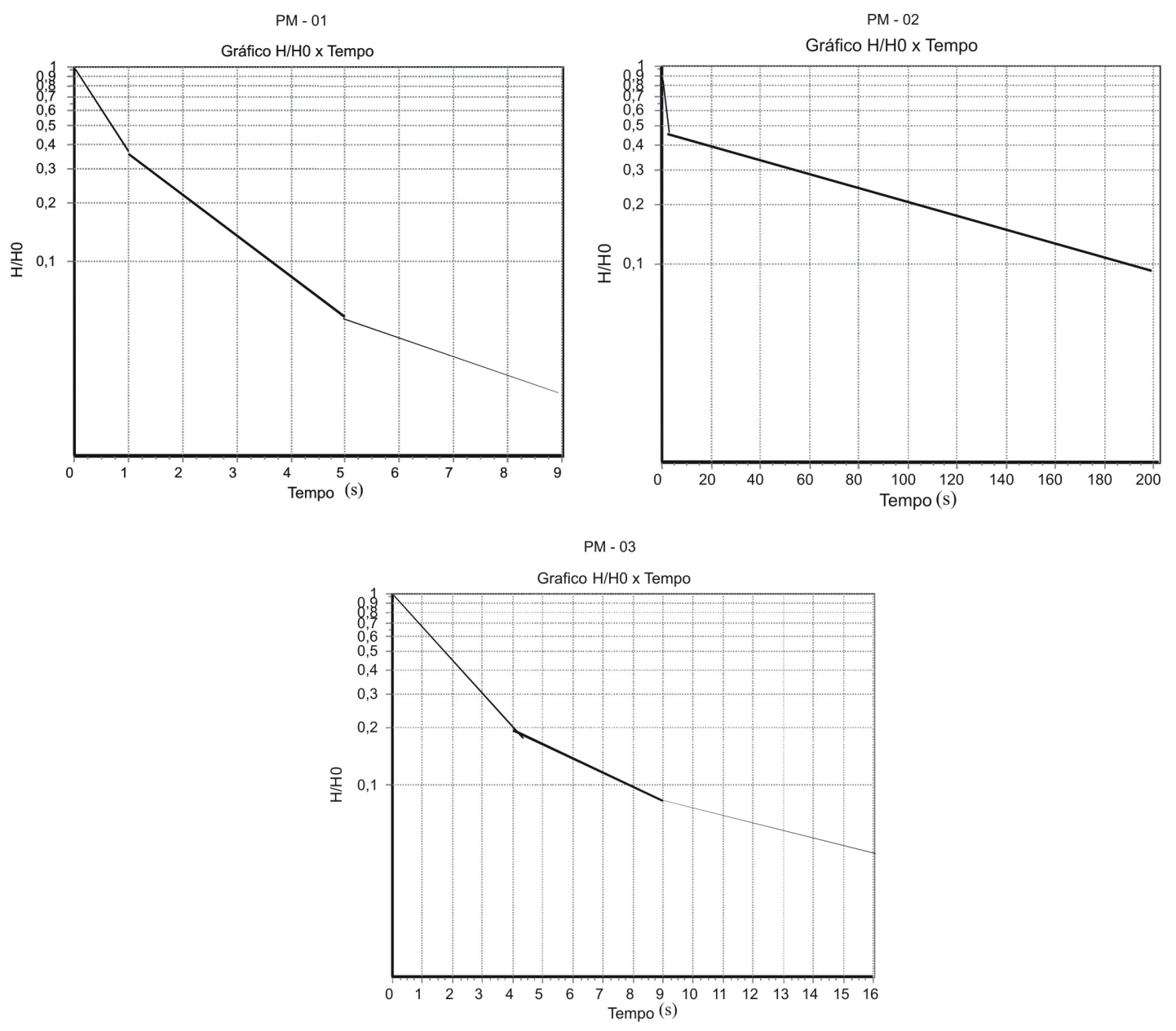

Figura 13 - Gráficos representando os testes de slug realizados nos poços de monitoramento PM-01, PM-02 e PM-03.

Figure 13 - Graphs showing slug tests executed in the monitoring wells PM-01, PM-O an, PM-03.

O método de Hazen, no entanto, superestimou os valores de condutividade hidráulica, provavelmente porque se baseia unicamente no diâmetro efetivo do grão, não levando em conta outras características texturais.

O método de Shepherd que utilizou análise granulométrica das amostras recuperadas no poço de monitoramento PM-01, na zona saturada, apresenta concentração de valores de condutividade hidráulica situada entre $8 \times 10^{-3}$ $\mathrm{cm} / \mathrm{s}$ e $1 \times 10^{-2} \mathrm{~cm} / \mathrm{s}$ (Figura 14), aproximando-se do valor obtido no teste de slug efetuado nesse mesmo poço, que foi de $7,71 \times 10^{-3} \mathrm{~cm} / \mathrm{s}$. Este resultado mostra que, por tratar-se de método expedito e menos oneroso, pode ser bem aplicado aos depósitos da Formação Rio Claro.
Método de Shepherd - Zona Saturada x Zona Não Saturada

Comparando a frequiência das condutividades hidráulicas das zonas não saturada (de $3 \mathrm{~m}$ a $7 \mathrm{~m}$ de profundidade) e saturada $(7,5 \mathrm{~m}$ a $18 \mathrm{~m}$ de profundidade) do poço de monitoramento PM-01, utilizando o método de Sherphed, observa-se pequena variação na distribuição dos valores de condutividade da zona saturada, em relação à não saturada (Figura 14).

A zona saturada possui uma classe de condutividade entre $4 \times 10^{-3} \mathrm{~cm} / \mathrm{s}$ e $6 \times 10^{-3} \mathrm{~cm} / \mathrm{s}$, que não está presente na zona não-saturada. $\mathrm{O}$ número de amostras com condutividade situada entre $8 \times 10^{-3} \mathrm{~cm} / \mathrm{s}$ e $1 \times 10^{-2} \mathrm{~cm} / \mathrm{s}$, na zona saturada, é quase duas vezes maior que na zona não saturada, sendo que os sedimentos mais arenosos na zona saturada. 

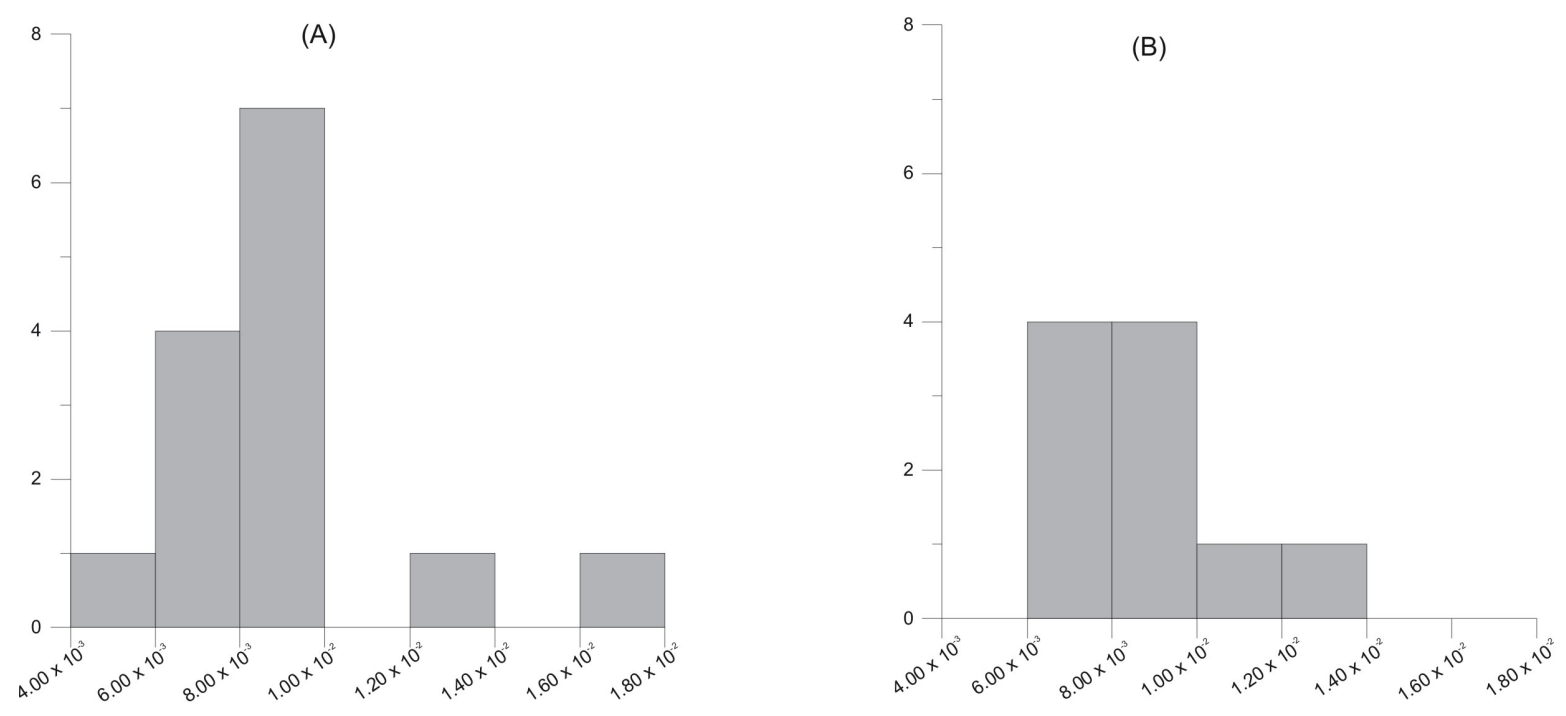

Figura 14 - Histogramas representando as freqüências de condutividade hidráulica na zona saturada (A) e na zona não saturada $(\mathrm{B})$.

Figure 14 - Histograms showing the frequencies of hydraulic conductivity determined in saturated zone (A) and in insaturated zone $(B)$.

\section{Método de Shepherd x Método de Guelph na Zona}

\section{Não Saturada}

Novamente, comparando as condutividades hidráulicas da zona não-saturada (de $3 \mathrm{~m}$ a $7 \mathrm{~m}$ de profundidade) obtidas pelo método de Shepherd, com as obtidas pelo método Guelph, observa-se uma discrepância acentuada na distribuição de valores (Figura 15).

O método Guelph foi utilizado em amostras in situ a $1 \mathrm{~m}$ de profundidade, onde os sedimentos da Formação Rio Claro estão bastante alterados. Os baixos valores de condutividade, determinados pelo método Guelph, se devem provavelmente à maior presença de grãos de fração argila nas amostras in situ, situadas a $1 \mathrm{~m}$ de profundidade.

Dessa forma, não se pode comparar esses resultados com aqueles do método de Shepherd, que utilizou sedimentos mais profundos, menos alterados e parcialmente consolidados, com menor quantidade de argila.

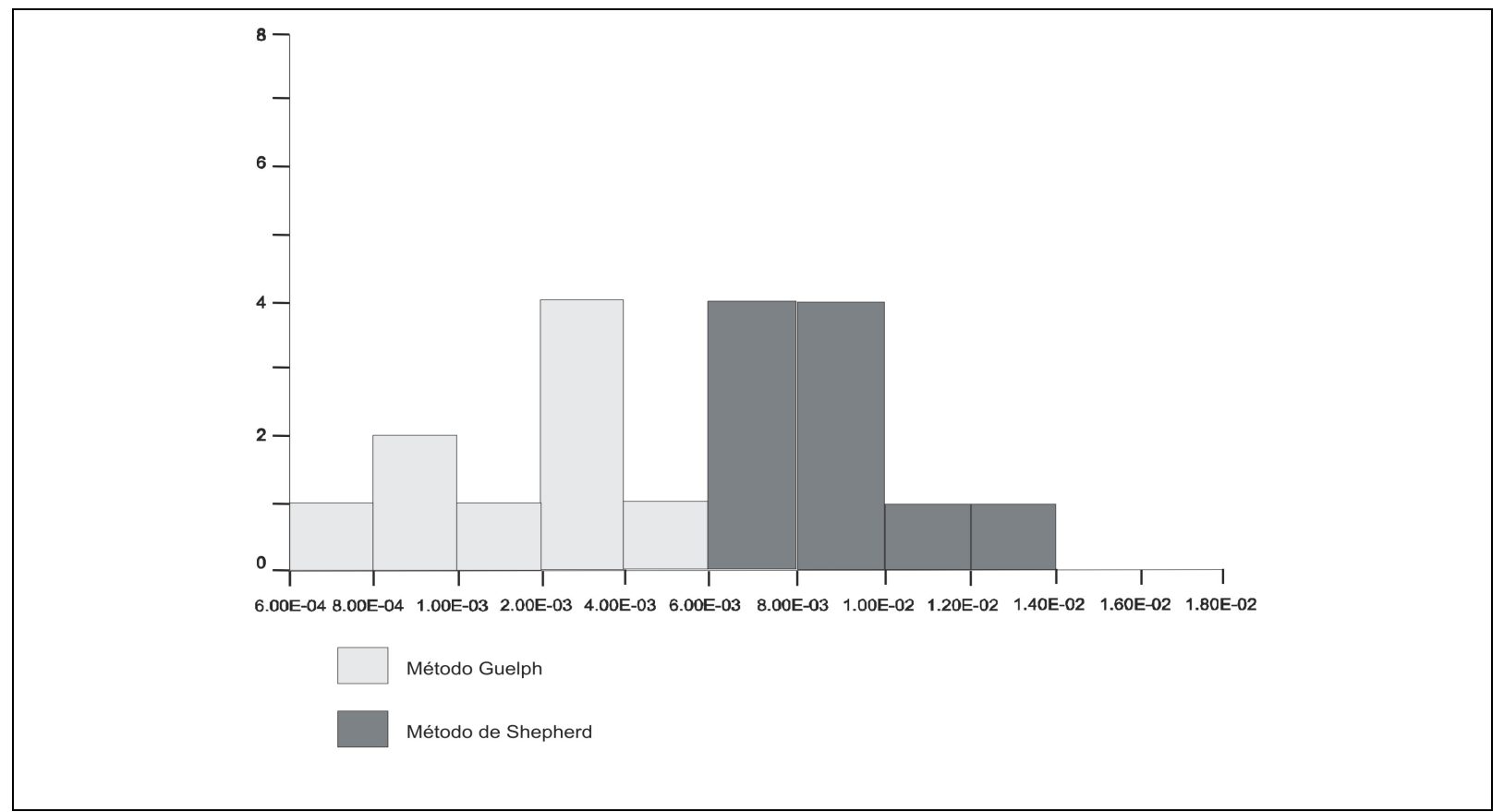

Figura 15 - Histograma representando as freqüências de condutividade hidráulica na zona não saturada pelos métodos Guelph e de Shepherd.

Figure 15 - Histogram showing the frequencies of hydraulic conductivity determined in insaturated zone using Guelph and Shepherd methods. 


\section{CONCLUSÕES}

Foram realizadas análises petrográficas de sedimentos da Formação Rio Claro, recuperados durante a perfuração de 03 poços de monitoramento no Campus da Unesp, em Rio Claro, além de vários ensaios de permeabilidade utilizando diferentes métodos que foram comparados entre si. Estes ensaios permitiram determinar as propriedades hidráulicas do aqüífero Rio Claro, fornecendo mais especificamente a condutividade hidráulica.

A Formação Rio Claro, segundo a análise petrográfica, é constituída predominantemente por arenitos, onde o principal constituinte detrítico do arcabouço é o quartzo.

Os métodos que utilizaram análise granulométrica para determinação da condutividade hidráulica apresentaram bons resultados. Somente o método de Hazen mostrouse mais discrepante ao superestimar os valores de condutividade hidráulica.

Isso se deve provavelmente à ênfase em considerar somente o diâmetro efetivo do grão como fator controlador da permeabilidade, não levando em conta outras características texturais. O método de Shepherd, aplicado às amostras da

zona saturada, recuperadas durante a perfuração do poço de monitoramento PM - 01, obteve uma maior concentração de valores de condutividade hidráulica situados entre $8 \times 10^{-3}$ $\mathrm{cm} / \mathrm{s}$ e $1 \times 10^{-2} \mathrm{~cm} / \mathrm{s}$, semelhante ao resultado obtido no teste de slug, efetuado nesse mesmo poço, que foi de $7,71 \times 10^{-3} \mathrm{~cm} / \mathrm{s}$, mostrando que por ser um método expedito e menos oneroso, pode ser utilizado com grande vantagem na Formação Rio Claro.

\section{AGRADECIMENTOS}

Agradecemos a FAPESP, pelo auxílio à pesquisa através da bolsa de mestrado e de recursos de reserva técnica (processo $\mathrm{n}^{0}$ 00/01396-5), e ao Departamento de Geologia Aplicada - IGCE/Unesp - Rio Claro por ceder os equipamentos e acessórios necessários para a realização dos ensaios. 


\section{REFERÊNCIAS}

ALMEIDA, F. F. M.; BARBOSA, O. Geologia das quadrículas de Piracicaba e Rio Claro, Estado de São Paulo. Bol. Div. Geol. Min. DNPM, n. 143, p. 1-96, 1953.

BJORNBERG, A.; LANDIM, P. M. B. Contribuição ao estudo da Formação Rio Claro (neocenozóico). Boletim Sociedade Brasileira Geologia, São Paulo (SP), v. 4, n. 15, p. 43-67, 1966.

BOUWER, H., R. C. RICE. A slug test for determining hydraulic conductivity of unconfined aquifers with completely or partially penetrating wells. Water Resources Research. Washington (DC), n. 12, p. 423-28, 1976.

BOUWER, H. The Bouwer and Rice slug test. Ground Water, n. 3, p. 304-309, 1989.

CHANG, H. K.; CARRIER, N. D. Winslug Programa de Aquisição e Tratamento Automatizado de Testes de Slug. Unesp Fundunesp, 2000. Registro INPI \# 000332760.

DAEE. Estudo de Águas Subterrâneas. São Paulo:1981. Departamento de Águas e Energia Elétrica do Estado de São Paulo.Projeto Concluído. Área: Campinas.

DAWSON, K. J., JONATHAN, I. D. Aquifer Testing: Design and Analysis of Pumping and Slug Tests. Chelsea: Lewis, 1991.

FETTER, C. W. Applied Hidrogeology. New Jersey, 1988.

FOLK, R. L. Petrology of sedimentary rocks. Austin: Hemphill's, 1968.

FREITAS, R. O., MEZZALIRA, S., ODA, G. H., VIEIRA, P. C., TORRES, C. C., HACHIRO, J., TOMINAGA, L. K., DEHIRA, L. K., MASSOLI, M.,
AZEVEDO, A. A. B., PRESSINOTI, M. M. N. Projeto levantamento geológico de formações superficiais. In: SIMPÓSIO REGIONAL DE GEOLOGIA. SBG, (1979, Rio Claro), v.2, p.263277.1979.

FRIEDMAN, M. G.; SANDERS E. J. Principles of Sedmentology. Estados Unidos, 1978.

FÚlFARO, V. J.; SUGUIO, K. A Formação Rio Claro, (Neo-cenozóico), e seu ambiente de deposição. Boletim Instituto Geográfico e Geológico, São Paulo (SP) n. 20, p. 45-60, 1968.

HAZEN, A. Discussion: Dams on sand foundations. American Society of Civil Engineers, n.73, p. 199, 1911.

HVORSLEV, M. J. Time lag and soil permeability in ground water observations. Buletim Army Corps of Engineers Waterway Experimentation Station, U. S. n. 36, 1951.

MELO, S. M.; COIMBRA, M.A.; CUCHIERATO, G. Fácies Sedimentares da Formação Rio Claro, Neocenozóico da Depressão Periférica Paulista. Revista IG. São Paulo (SP), v. 2, n. 18, p. 49-63, 1997.

OLIVA, A. Estudo Hidrogeológico da Formação Rio Claro no Município de Rio Claro - SP. São Paulo, 2002. Dissertação de Mestrado. Instituto de Geociências e Ciências Exatas - UNESP.

SHEPHERD, R.G. Correlations of Permeability and Grain Size. Groundwater, v. 5, n. 27, p. 633-638, 1989.

SOIL MOISTURE CORP. Guelph Permeameter: Operating Instructions. Santa Bárbara, 1991. 
Determinação da condutividade hidráulica da Formação Rio Claro:

análise comparativa através de análise granulométrica. e ensaios com permeâmetro guelph e testes de slug 